\title{
A Peculiar New Genus of Bibionomorpha (Diptera) with Brachycera-Like Modification of Antennae from Mid-Cretaceous Amber of Myanmar
}

\author{
Jan Ševčík ${ }^{1, *}$, John Skartveit ${ }^{2}$, Wiesław Krzemiński ${ }^{3}{ }^{3}$ and Kornelia Skibińska ${ }^{3}$ \\ 1 Department of Biology and Ecology, Faculty of Science, University of Ostrava, Chittussiho 10, \\ 71000 Ostrava, Czech Republic \\ 2 Department of Teacher Education, NLA University College Bergen, P.O. Box 74 Sandviken, \\ 5812 Bergen, Norway; John.Skartveit@NLA.no \\ 3 Institute of Systematics and Evolution of Animals, Polish Academy of Sciences, Sławkowska 17, \\ 31-016 Kraków, Poland; wieslawk4@gmail.com (W.K.); yukisiak@gmail.com (K.S.) \\ * Correspondence: sevcikjan@hotmail.com
}

check for

updates

Citation: Ševčík, J.; Skartveit, J.; Krzemiński, W.; Skibińska, K. A Peculiar New Genus of

Bibionomorpha (Diptera) with Brachycera-Like Modification of Antennae from Mid-Cretaceous Amber of Myanmar. Insects 2021, 12, 364. https://doi.org/10.3390/ insects12040364

Academic Editor: Peter H. Adler

Received: 7 March 2021

Accepted: 17 April 2021

Published: 20 April 2021

Publisher's Note: MDPI stays neutral with regard to jurisdictional claims in published maps and institutional affiliations.

Copyright: (c) 2021 by the authors. Licensee MDPI, Basel, Switzerland. This article is an open access article distributed under the terms and conditions of the Creative Commons Attribution (CC BY) license (https:/ / creativecommons.org/licenses/by/ $4.0 /)$.
Simple Summary: The mid-Cretaceous amber of Myanmar (also known as Burmese amber) is almost 100 MYA old and represents an invaluable source of information about the evolution of life in the late Mesozoic. This is particularly true for the early flies (lower Diptera) which underwent rapid radiation during the Cretaceous period. Here we describe a remarkable nematocerous fossil fly which shows a character typical of the flies of the suborder Brachycera-with strongly modified antenna-representing new evidence that such a Brachycera-like modification of the antennae has evolved several times during the evolutionary history of Diptera.

Abstract: A new fossil genus of Bibionidae (Diptera: Bibionomorpha), Burmahesperinus gen. nov., from the mid-Cretaceous Burmese amber, is described and illustrated (type species Burmahesperinus antennatus sp. nov., the other two species included are B. conicus sp. nov. and B. pedicellatus sp. nov.). The new genus is tentatively placed in a new subfamily, Burmahesperininae subfam. nov. of the family Bibionidae. Its possible phylogenetic position is briefly discussed. The new genus, as well as the subfamily, possesses the wing venation similar to the recent genus Hesperinus Walker, 1848, in combination with Brachycera-like modification of both the male and female antenna and the overall habitus typical of fungus gnats (Sciaroidea).

Keywords: fossil insects; Bibionidae; inclusions; Mesozoic; taxonomy; new genus; modified antenna

\section{Introduction}

Representatives of the dipteran infraorder Bibionomorpha belong to the most common insects in the fossil record, as well as in recent fauna. There are some 16,500 described species of Bibionomorpha in 34 families and almost 1400 genera, out of which approximately 1400 species are fossil [1,2]. The oldest described fossil taxa assigned to Bibionomorpha sensu lato come from the Late Triassic (ca. 220 Mya) of Virginia, USA, and from the Madygen Formation of South Fergana, Kyrgyzstan, dated as Middle or Late Triassic [3-5].

Although the phylogenetic interrelationships within the infraorder are far from being clarified [6], Bibionomorpha in its strictest sense (Bibionoidea + Sciaroidea) currently comprises 11 extant families plus approximately the same number of exclusively fossil families $[1,2,6,7]$. These numbers already reflect the inclusion of the former families Lygistorrhinidae and Cascopleciidae into Keroplatidae and Bibionidae, respectively [2,7].

The mid-Cretaceous (Cenomanian) amber of northern Myanmar (Burmese amber) is considered as essential for understanding the origins and diversification of recent families of Sciaroidea [8], and most probably this applies also to the entire infraorder Bibionomorpha. However, apart from the families Mycetophilidae and Keroplatidae, with 16 described 
species in total [8,9], little attention has been devoted to the study of the other taxa of Bibionomorpha in Burmese amber and in the Cretaceous as a whole. In contrast, there are numerous taxa of Bibionomorpha described from Jurassic compression fossils [10,11]. Most recently, a new lower Cretaceous subfamily, Cretobibioninae Skartveit and Ansorge 2020, was established [12], representing one of the few recently described Cretaceous taxa of Bibionidae. The other example is the Burmese amber genus Cascoplecia Poinar, 2010 [13], initially described in a separate family but later transferred by Pape et al. 2011 [2] to Bibionidae.

The concept of the family Bibionidae differs among authors. North American authors $[14,15]$ have usually preferred a traditional broad concept of Bibionidae, i.e., including the subfamily Hesperininae, while European authors mostly prefer narrower concepts of the families [16], recognizing the separate family Hesperinidae and sometimes even Pleciidae [17]. Actually, most subfamilies in Bibionidae sensu lato (with the exception of Bibioninae) are monogeneric and their synapomorphies are the same as for the genera included. Diagnoses, descriptions, and morphological synapomorphies of all extant genera of Bibionidae were given by Fitzgerald [18] and Pinto and Amorim [19].

In this paper, we describe a new fossil genus of Bibionomorpha possessing a very unusual feature-modified antennal flagellum in both sexes-a feature typical for the flies of the suborder Brachycera, with the only other examples hitherto known within the lower Diptera (Nematocera) being two genera of the fossil family Archizelmiridae [20]. We tentatively place this new genus in a new subfamily of Bibionidae.

\section{Materials and Methods}

Specimens were examined using a Nikon (Minato, Japan) SMZ25 stereomicroscope equipped with a Nikon DS-Ri2 digital camera. Photomicrographs are focus stacks captured using this system and processed using NIS-Elements Imaging Software. Line drawings were produced by tracing photographs or with a drawing apparatus attached to the microscope. The terminology principally follows that of Fitzgerald [15] and Skartveit [16], while the terms of wing venation are mainly after Krzemińska et al. [21]. For the explanation of the wing vein nomenclature used in this paper, see the last paragraph of the Discussion below. All the holotypes come from the Hukawng Valley in Kachin State [22,23], northern Myanmar, and they are deposited in the Institute of Systematics and Evolution of Animals, Polish Academy of Sciences, Kraków, Poland (ISEA PAS). Burmese amber is dated to the earliest Cenomanian $(98.79 \pm 0.62 \mathrm{Ma})$, based on $\mathrm{U}-\mathrm{Pb}$ dating of zircons from the volcaniclastic matrix of the amber [24].

This published work and the nomenclatural acts it contains have been registered in ZooBank, the online registration system for the ICZN (International Code of Zoological Nomenclature). The LSID (Life Science Identifier) for this publication is: LSIDurn: lsid:zoobank.org:pub: 583EB8BF-DD8A-4878-BFC9-23682403E035.

\section{Results}

3.1. Systematic Paleontology

Order Diptera Linnaeus, 1758

Infraorder Bibionomorpha Hennig, 1954

Superfamily Bibionoidea Fleming, 1821

Family Bibionidae Fleming, 1821

\subsection{Description of a New Fossil Material}

Subfamily Burmahesperininae subfam. nov.

LSID urn:lsid:zoobank.org:act:A7F7E953-1275-4875-B7A9-CCA0C2AFDBC9

Type genus: Burmahesperinus gen. nov.

Type species: Burmahesperinus antennatus sp. nov.

Genera included: Burmahesperinus gen. nov. 
Diagnosis. Relatively small and slender bibionoid flies (Figure 1), resembling both Bibionoidea and Sciaroidea. Body not distinctly hairy. Both male and female antennae about as long as the breadth of the head, flagellum strongly modified, filiform, tapering to the apex. Flagellomeres distinctly differentiated, with the basal segments thicker and the apical segments tapered to a hair-like process (stylus). Wing (Figure 2A) without stigma, with radial veins slightly more chitinized than the other veins. Vein Sc relatively long, ending in $C$ around the middle of the wing and well beyond the level of Rs; $R_{2+3}$ short, not distinctly sinuous; crossvein called bm-m absent (actually basal part of $\mathrm{M}_{3+4}$ ); $\mathrm{M}_{1+2}$ long, almost as long as $\mathrm{M}_{2} ; \mathrm{A}_{1}$ long but weak, reaching the wing margin. All legs thin and without strong spines, each tibia with a single short tibial spur, not longer than maximum tibial diameter. Coxae short, femora not thickened. Male terminalia with a relatively long gonocoxite, bearing gonostylus about as long as gonocoxite. Gonostylus is simple, apically blunt or with a subapical tooth.

\section{Burmahesperinus gen. nov.}

LSID urn:Isid:zoobank.org:act:74A40C8B-E9AE-4DD2-B223-88FDDC6E20F7

Type species: Burmahesperinus antennatus sp. nov., by monotypy and present designation. Diagnosis. The same as for the subfamily.

Etymology. The name of the new genus is composed of Burma (=Myanmar), referring to the origin of the amber, and Hesperinus, a similar extant genus.

Burmahesperinus antennatus sp. nov. (Figures 1A, 2A, 3A and 4A)

LSID urn:lsid:zoobank.org:act: 4986BA76-962D-41E9-B5E2-81E692CB1BB7

Material. Holotype No. MP/4078, male, in Burmese amber (the earliest Cenomanian, $98.79 \pm 0.62 \mathrm{Ma}$ ), deposited in the Institute of Systematics and Evolution of Animals, Polish Academy of Sciences, Kraków, Poland (ISEA PAS).

Diagnosis. Scapus and pedicel tubular, almost of the same width; Sc slightly shorter than half of the length of the wing; $R_{1}$ ends in $C$ well before the base of $R_{2+3}$ and is shorter than a half of the wing length; $R_{2+3}$ about 1.5 times as long as Rs.

Etymology. The name antennatus refers to the peculiar structure of the male antenna.

Description (male). Body $2.2 \mathrm{~mm}$ long; wing length $2.0 \mathrm{~mm}$.

Head relatively small, with eyes widely separated; all ommatidia of the same size. Ocelli present but their details not traceable.

Antenna (Figure 2A) slightly longer than the breadth of the head; scapus long, tubular; pedicel short, tubular, about as broad as scapus; the basal segment of the flagellum wide, short, perhaps formed by the fusion of several segments of the basal flagellomeres, the subsequent segments increasingly thinner and elongated, forming a stylus with only poorly visible boundaries between the segments.

Palpus with four visible palpomeres of similar length; all of them thin and relatively long.

Thorax slightly arched, about 1.5 times as long as high. Scutum and lateral sclerites mostly bare, without distinct hairs or spines.

Wing (Figure 3A): 3.2 times as long as wide. Wing membrane hyaline, without macrotrichia and without stigma or other markings. Radial veins relatively strong and thickened; $C$ ends beyond the apex of $R_{5}$, reaching to about a third of the distance between the apex of $R_{4+5}$ and $M_{1}$; Sc ends in $C$ just before the half of the wing length; $R_{1}$ ends in $C$ well before the base of $R_{2+3} ; R_{2+3}$ about 1.5 times as long than $R s ; R_{4+5}$ almost four times as long as $R_{2+3}$; r-m at the level of the base of $\mathrm{M}_{3+4+\mathrm{m} \text {-cu }}$; vein $\mathrm{M}_{3+4+\mathrm{m} \text {-cu }}$ by $1 / 3$ longer than the section of $\mathrm{Cu}$ located beyond the base of $\mathrm{M}_{3+4+\mathrm{m} \text {-cu; }}$; cell $\mathrm{M}_{3+4}$ approximately 1.25 as wide as $\mathrm{M}_{2}$ cell.

Legs relatively long, thin, with the coxae short and femora at least ten times as long as broad. Legs covered with dense short setae, without any strong spines. Each leg with a single tibial spur, not longer than maximum tibial diameter.

Abdomen sparsely covered with relatively short hairs.

Male terminalia (Figure 4A) as in most Bibionidae, except for the longer and narrower gonocoxite. Tergite 9 relatively short, about twice as broad as long, with a slightly cleft 
posterior margin (external); cerci about as long as gonocoxites, bearing long thin setae; gonocoxite broad at the base, sickle shaped and tapering towards the apex, with a clear extension in the basal part and additionally extended in $1 / 3$ of its length; gonostylus wide, plane-like, tapering towards the apex. Internal structures of terminalia are not traceable in the holotype.

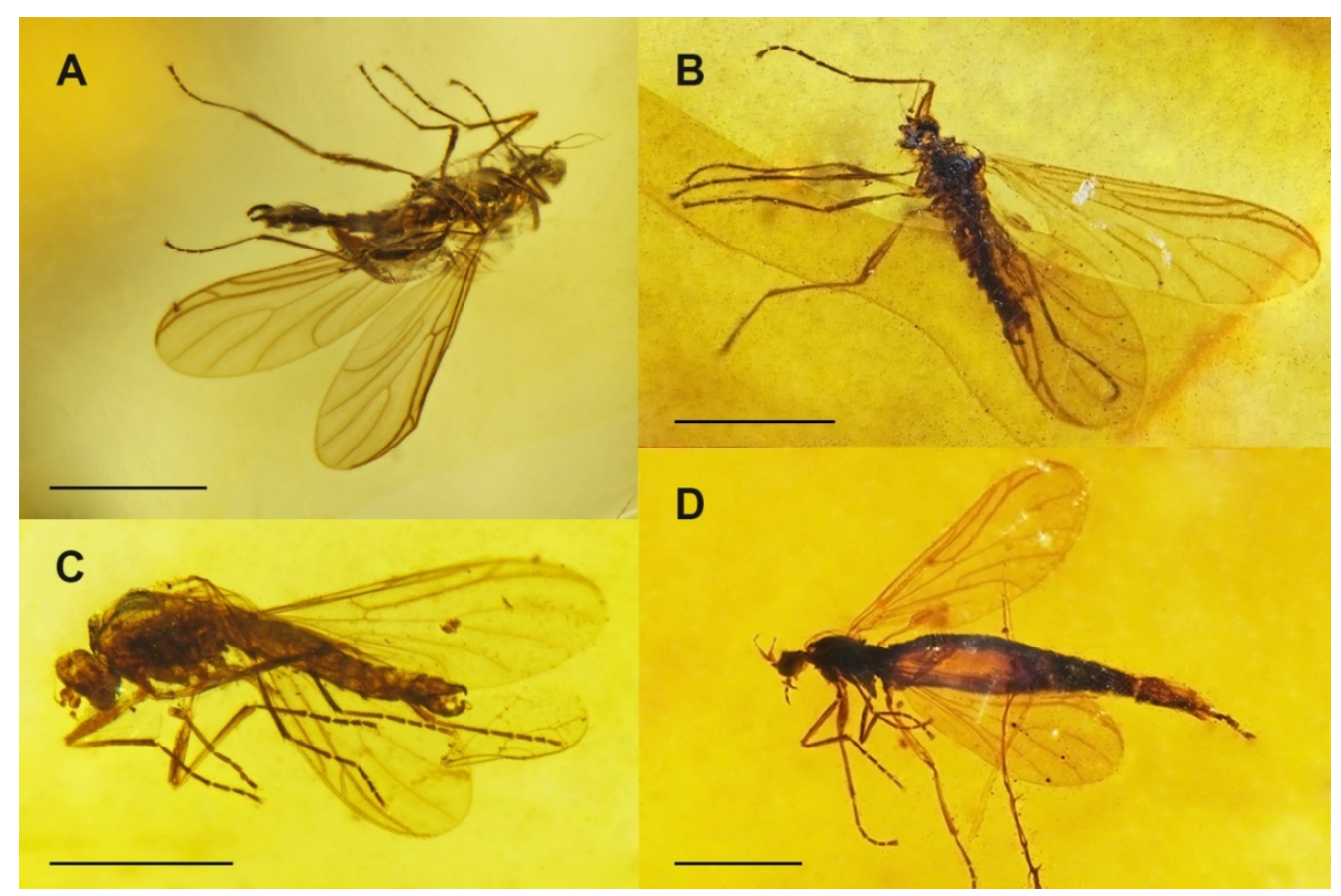

Figure 1. Habitus photographs of Burmahesperinus antennatus gen. et sp. nov. ((A), holotype), B. conicus gen. et sp. nov. ((B), holotype), B. pedicellatus gen. et sp. nov. ((C), holotype), and Burmahesperinus sp. ((D), female specimen No. MP/4081). Scale bars $=1 \mathrm{~mm}$.

Burmahesperinus conicus sp. nov. (Figures $1 \mathrm{~B}, 2 \mathrm{~B}, 3 \mathrm{~B}$ and $4 \mathrm{~B}, \mathrm{C}$ )

LSID urn:lsid:zoobank.org:act: 5526B751-8148-46BA-8513-79BDA6CB5E52

Material. Holotype No. MP/4079, male, in Burmese amber (the earliest Cenomanian, $98.79 \pm 0.62 \mathrm{Ma}$ ), deposited in the Institute of Systematics and Evolution of Animals, Polish Academy of Sciences, Kraków, Poland (ISEA PAS).

Diagnosis. Scapus and pedicel apparently fused, forming a uniform conical structure narrowing towards the apex; $S c$ slightly longer than half the length of the wing; $R_{1}$ ends in $\mathrm{C}$ almost at the level of the base of $\mathrm{R}_{2+3} ; \mathrm{R}_{2+3}$ about as long as Rs.

Etymology. The name conicus refers to the conical shape of the fused basal segments of the male antenna.

Description. Body $1.8 \mathrm{~mm}$ long; wing length $2.3 \mathrm{~mm}$.

Head relatively small, with eyes widely divided; all ommatidia of the same size. Ocelli present but their details not traceable.

Antenna (Figure 2B) slightly longer than the width of the head; scapus and pedicel joined, forming a uniform structure wide at the base and narrowing towards the apex; the first flagellomere broad, bowl-shaped, short and perhaps formed by the fusion of several segments of the basal flagellomeres, the subsequent flagellomeres are thinner and more elongated, forming a flagellum with poorly visible boundaries between the segments.

Palpus with four visible palpomeres of similar length; all of them thin and relatively long.

Thorax slightly arched, about 1.5 times as long as high. Scutum and lateral sclerites mostly bare, without distinct hairs or spines.

Wing (Figure 3B): 3.1 times as long as wide. Wing membrane hyaline, without macrotrichia and without stigma or other markings. Radial veins relatively strong and 
thickened; $C$ ends slightly beyond the apex of $R_{5}$, reaching to about $1 / 4$ of the distance between the apex of $R_{4+5}$ and $M_{1}$; Sc longer than half of the wing length; $R_{1}$ ends in $C$ almost at the level of the base of $R_{2+3} ; R_{2+3}$ about as long as $R s ; R_{4+5}$ almost four times as long as $\mathrm{R}_{2+3}$; $\mathrm{r}-\mathrm{m}$ clearly beyond the base of $\mathrm{M}_{3+4+\mathrm{m} \text {-cu }}$; vein $\mathrm{M}_{3+4+\mathrm{m}-\mathrm{cu}}$ about $1 / 3$ longer than the section of $\mathrm{Cu}$ located beyond the base of $\mathrm{M}_{3+4+\mathrm{m}-\mathrm{cu}}$; cell $\mathrm{M}_{3+4}$ slightly narrower than cell $\mathrm{M}_{2}$.

Legs relatively long, thin, covered with setae, each leg with a single tibial spur, about as long as maximum tibial diameter.

A

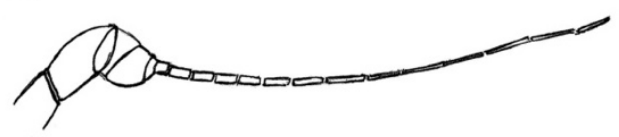

C

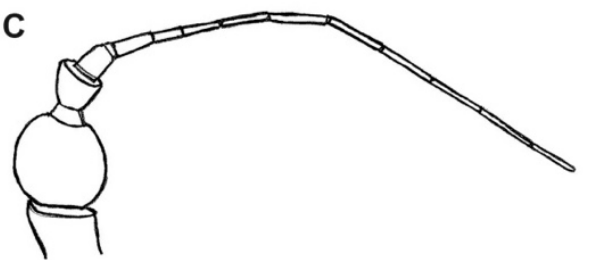

B

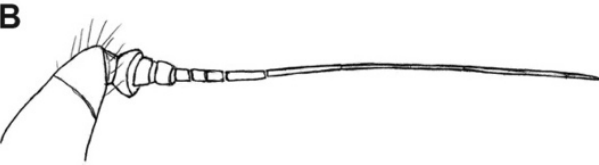

D

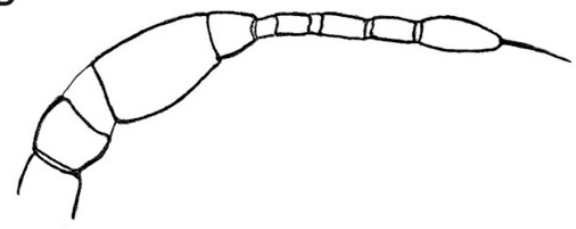

Figure 2. Antenna of Burmahesperinus antennatus gen. et sp. nov. ((A), holotype), B. conicus gen. et sp. nov. ((B), holotype), B. pedicellatus gen. et sp. nov. ((C), holotype), and Burmahesperinus sp. ((D), female specimen No. MP/4081).
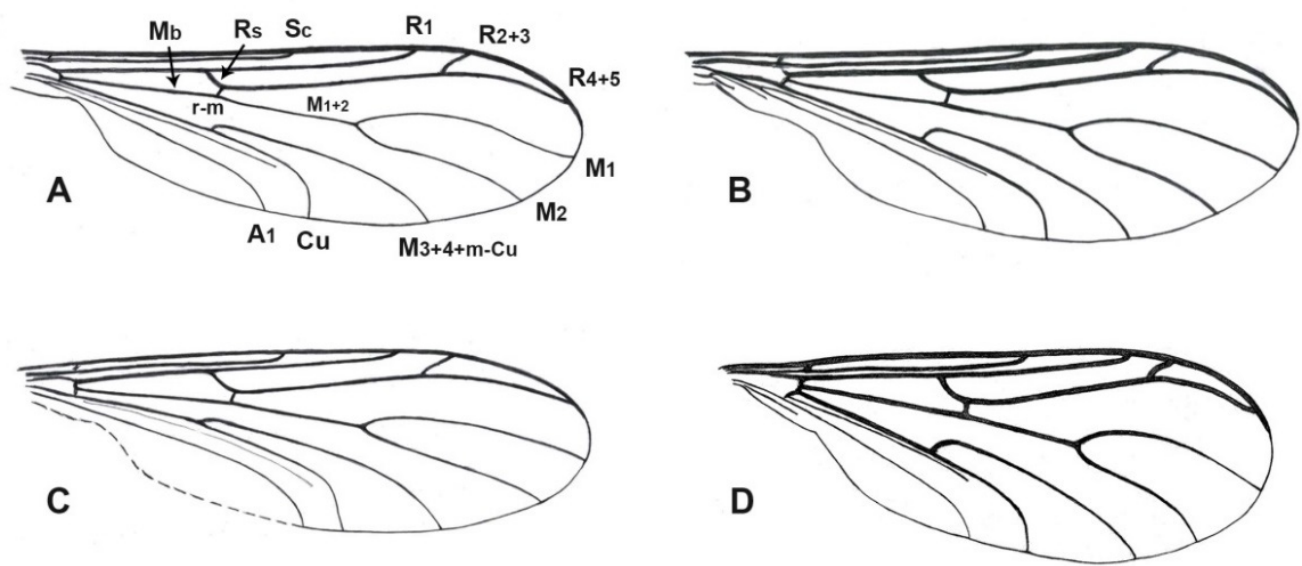

Figure 3. Wing of Burmahesperinus antennatus gen. et sp. nov. ((A), holotype), B. conicus gen. et sp. nov. ((B), holotype), B. pedicellatus gen. et sp. nov. ((C), holotype), and Burmahesperinus sp. ((D), female specimen No. MP/4081). Abbreviations: Sc, subcostal vein; Rs, radial sector; $\mathrm{R}_{1-5}$, branches of radius; $r-m$, radial-medial crossvein; $\mathrm{Mb}$, medial-basal vein; $\mathrm{M}_{1+2}$, stem of media; $\mathrm{M}_{1,2}$, branches of media; $\mathrm{M}_{3+4+\mathrm{m}-\mathrm{cu}}$, branches of media fused with crossvein $\mathrm{m}-\mathrm{cu} ; \mathrm{Cu}$, cubital vein; $\mathrm{A}_{1}$, first branch of anal vein. Scale bar $=0.5 \mathrm{~mm}$.

Male terminalia (Figure 4B,C) as in most Bibionidae, except for the longer and narrower gonocoxite. Tergite 9 relatively short, about twice as broad as long, with a slightly cleft posterior margin (external); cerci about as long as gonocoxites, bearing long, thin setae; gonocoxite broad at the base, sickle shaped, basally broad but without any additional extension in $1 / 3$ of its length; gonostylus wide, plane shaped, with a distinct fork apically. The gonostyli appear as asymmetrical in the type specimen, with the left and right 
gonostylus different apically (Figure 4C). Internal structures of terminalia are not traceable in the holotype.

Burmahesperinus pedicellatus sp. nov. (Figures 1C, 2C, 3C and 4D,E)

LSID urn:lsid:zoobank.org:act: 96E70BF5-DB94-40E4-A631-9689CCF791E9

Material. Holotype No. MP/4080, male, in Burmese amber (the earliest Cenomanian, $98.79 \pm 0.62 \mathrm{Ma}$ ), deposited in the Institute of Systematics and Evolution of Animals, Polish Academy of Sciences, Kraków, Poland (ISEA PAS).

Diagnosis. Scapus long, tubular; pedicel relatively large, spherical; Sc much shorter than half the wing length; $\mathrm{R} 1$ ends in $\mathrm{C}$ well before the base of $\mathrm{R}_{2+3} ; \mathrm{R}_{2+3}$ only slightly longer than Rs.

Etymology. The name pedicellatus refers to the unusual spherical shape of the pedicel.

Description. Body $2.3 \mathrm{~mm}$ long; wing length $2.1 \mathrm{~mm}$.

Head relatively small, with eyes widely divided; all ommatidia of the same size. Ocelli present but their details not traceable.

Antenna (Figure 2C) slightly longer than the width of the head; scapus long, tubular; pedicel very large, globular; the first flagellomere broad, bowl shaped, short, the subsequent parts are thinner and more elongated, forming a flagellum with poorly visible boundaries between the segments.

Palpus with four visible palpomeres of similar length; all of them thin and relatively long.

Thorax slightly arched, about 1.5 times as long as high. Scutum and lateral sclerites mostly bare, without distinct hairs or spines.

Wing (Figure 3C): 3.1 times as long as wide. Wing membrane hyaline, without macrotrichia and without stigma or other markings. Radial veins relatively strong and thickened; Sc significantly shorter than half of the wing length; ends in $C$ well before the base of $\mathrm{R}_{2+3} ; \mathrm{R}_{2+3}$ is only slightly longer than $\mathrm{Rs} ; \mathrm{R}_{4+5}$ almost four times as long as $\mathrm{R}_{2+3}$; $\mathrm{r}-\mathrm{m}$ is well beyond the base of $\mathrm{m}-\mathrm{cu}+\mathrm{M}_{3+4} ; \mathrm{m}-\mathrm{cu}+\mathrm{M}_{3+4}$ twice as long as the section of $\mathrm{Cu}$ located beyond the base of $\mathrm{m}-\mathrm{Cu}+\mathrm{M}_{3+4}$; cell $\mathrm{M}_{3+4}$ equals the width of the opening of the cell $\mathrm{M}_{2}$.

Legs relatively long, thin, covered with setae, each leg with a single tibial spur, about as long as maximum tibial diameter.

Male terminalia (Figure 4D,E) as in most Bibionidae, except for the longer and narrower gonocoxite. Tergite 9 relatively short, about twice as broad as long, with a deeply cleft posterior margin; cerci about as long as gonocoxites, bearing long thin setae; gonocoxite narrow basally, clearly extended in the middle of its length; gonostylus broad basally, flattened, narrowing towards the end. Internal structures of terminalia are not traceable in the holotype.

Burmahesperinus sp. (female) (Figures 1D, 2D, 3D and 4F)

Material. Specimen No. MP/4081, female, in Burmese amber (the earliest Cenomanian, $98.79 \pm 0.62 \mathrm{Ma}$ ), deposited in the Institute of Systematics and Evolution of Animals, Polish Academy of Sciences, Kraków, Poland (ISEA PAS).

Description. Body $3.8 \mathrm{~mm}$ long; wing length $2.2 \mathrm{~mm}$.

Similar to male in most characters.

Head relatively small, eyes dichoptic, widely separated, all ommatidia are of the same size. Ocelli placed on a prominent medial tubercle. Antenna (Figure 2D) strongly modified, tapering to the apex, shorter than the width of the head; scapus tubular; pedicel short; basal section of the flagellum large, broad, broader than the width of the pedicel, closely connected to the second section of the flagellum in the shape of an inverted bowl, and the next three sections narrow and rather short, while the last (sixth) section of the flagellum clearly extended and longer than the penultimate one with a long bristle at the end; palpi four-segmented, the last one over twice as long as the penultimate one.

Thorax slightly arched, about 1.5 times as long as high. Scutum and lateral sclerites mostly bare, without distinct hairs or spines. 
A

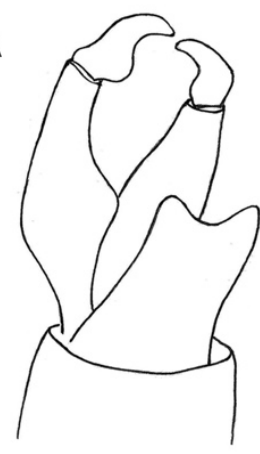

D

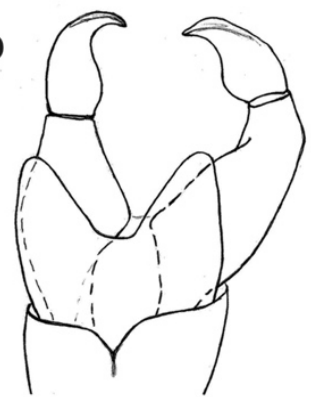

B

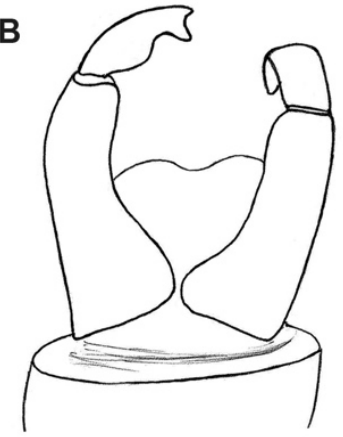

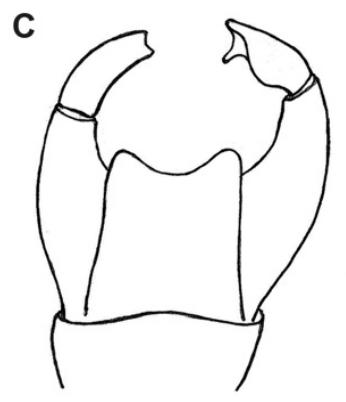

$\mathrm{E}$

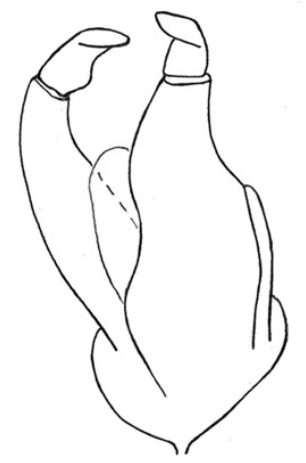

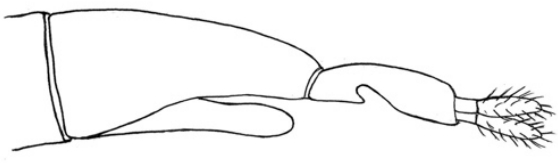

$\mathbf{F}$

Figure 4. Male and female terminalia of Burmahesperinus antennatus gen. et sp. nov. ((A), holotype), B. conicus gen. et sp. nov. ((B,C), holotype), B. pedicellatus gen. et sp. nov. ((D,E), holotype), and Burmahesperinus sp. (F), female specimen No. MP/4081). Dorsal (A,C,D), ventral (B) and lateral view $(\mathrm{E}, \mathrm{F})$.

Wing (Figure 3D): 2.7 times as long as wide. Wing membrane hyaline, without macrotrichia and without stigma or other markings. Radial veins relatively strong and thickened; $S c$ slightly longer than half of the wing length; $R_{1}$ ends in $C$ well before the base of $R_{2+3}$; Rs almost 1.5 times as long as $R_{2+3} ; R_{4+5}$ almost four times as long as $R_{2+3} ; r-m$ is well beyond the base of $\mathrm{M}_{3+4+\mathrm{m} \text {-cu; }} ; \mathrm{M}_{3+4+\mathrm{m} \text {-cu }}$ almost twice as long as the section of $\mathrm{Cu}$

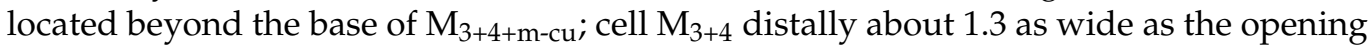
of the cell $\mathrm{M}_{2}$.

Legs relatively long, thin, covered with setae, each leg with a single tibial spur, about as long as maximum tibial diameter.

Abdomen elongated and swollen in basal half.

Terminalia as in Figure 4F.

Remarks. Currently, it is not possible to assign this female unequivocally to any species described here. This female shows a different way of the reduction and overall structure of the antennae than in the males described above. Perhaps it is another example of sexual dimorphism in Bibionidae, or the described female represents yet another unknown species of Burmahesperinus gen. nov. This problem can possibly be solved in the future with more specimens available. The wing venation may suggest this might be the female of $B$. conicus sp. nov. The features present in the latter species but different from those in both $B$. antennatus sp. nov. and B. pedicellatus sp. nov. include medial portion of $\mathrm{Cu}$ and proximal half of $\mathrm{M}_{3+4+\mathrm{m} \text {-cu }}$ parallel (diverging in the other two species) and the fork of $\mathrm{M}_{1}$ and $\mathrm{M}_{2}$ basally more rounded (narrow in the other two species). We prefer, however, to leave this female unassigned to a species, until more material is available and possible variation in wing vein characters is better known. 


\subsection{Identification Key to Species of Burmahesperinus gen. nov.}

1. Sc longer than half the wing length; $R_{1}$ ends in $C$ almost at the level of the base of $R_{2+3}$. Scapus and pedicel fused, forming a uniform conical structure $\ldots \ldots \ldots \ldots \ldots$

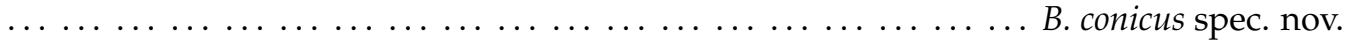

Sc shorter than half of the wing length. $R_{1}$ ends in $C$ before the base of $R_{2+3} \ldots \ldots 2$ 2. Scapus and pedicel tubular, almost of the same width ........ B. antennatus spec. nov. Scapus long, tubular; pedicel spherical B. pedicellatus spec. nov.

\section{Discussion}

A similar pattern of wing venation like in Burmahesperinus gen. nov. can be seen in the genus Hesperinus Walker, 1848, a genus based on the extant type species but known also from Baltic amber [25] or in several genera of the fossil family Pleciofungivoridae [10,11], e.g., in Eohesperinus Rohdendorf, 1946 or Pleciofungivora Rohdendorf, 1938. In all these taxa, however, the vein $R_{2+3}$ is substantially longer and sinuous, and the crossvein bm-m (according to [26] or bm-m sensu [16], actually the basal part of $\mathrm{M}_{3+4}$ ) is well developed, regardless of the typical nematoceran structure of the antennae. In extant species of Hesperinus, a distinct pterostigma is also present (although probably absent in some of the Baltic amber representatives [25]) and the stem of $\mathrm{M}$-fork $\left(\mathrm{M}_{1+2}\right)$ is distinctly shorter (while almost as long as $\mathrm{M}_{1}$ in Burmahesperinus). The extant species of Hesperinus are also substantially larger, with wing length being around five times as long as that of Burmahesperinus. On the other hand, both Burmahesperinus and Hesperinus share the narrow wing shape, with little developed anal lobe, dichoptic eyes in male (while the male eyes are holoptic in all the other extant Bibionoidea), and reduced mouthparts.

Additionally, several primitive extant genera of Sciaroidea show some similarities to Burmahesperinus in the ground plan of the wing venation, as well as in the relatively simple male terminalia, for example Arachnocampa Edwards, 1924; Bolitophila Meigen, 1818; and Catotricha Edwards, 1938, but proportions of particular veins (including the presence or absence of the crossvein bm-m sensu [26]) are different among these taxa, regardless of some other body characters typical of Sciaroidea. In particular, in most Sciaroidea (except of Cecidomyiidae), both the coxae and tibial spurs are much longer than in Burmahesperinus. However, in the broad and heterogeneous groups like Sciaroidea, unique synapomorphies defining the entire group are difficult or impossible to find, so the concept of these suprageneric taxa may differ among particular authors. This may potentially complicate the systematic placement of some peculiar fossil taxa, including Burmahesperinus. In any case, we do not prefer to place Burmahesperinus in Sciaroidea.

We have decided to place the new genus in the Bibionidae sensu lato, based mostly on the highly plesiomorphic wing venation similar to that in Hesperinus. However, its placement in the separate new subfamily Burmahesperininae should be considered as tentative, pending new discoveries in the fossil record, especially in the Mesozoic, which may change the concept and position of the new subfamily. Fitzgerald [18] suggested the complete postgenal bridge as a synapomorphy for Bibionidae but this character state is not traceable in most fossil specimens, including the type material of Burmahesperinus.

However, the most striking feature of the new genus is the strongly modified antenna, both in male and female. Within the lower Diptera (Nematocera), a similarly reduced antennal flagellum is present only in two genera of the entirely fossil family Archizelmiridae, viz. Burmazelmira [18] from Burmese amber and the Spanish Lower Cretaceous (upper Albian) amber [27] and Archimelzira [18] from the upper Cretaceous (Turonian) amber of New Jersey [18]. The antennal flagellum of Burmazelmira shows the highest degree of modification (stylus represents more than three distal quarters of the length of the flagellum), hitherto a unique example in the order Diptera outside the suborder Brachycera [18]. However, many other characteristics, including the shape of wing and wing venation (especially the quite different position of veins in the proximal half of a wing), rule out a possible placement of Burmahesperinus gen. nov. in Archizelmiridae. 
Evidently, such a modification of the antennae has evolved several times during the evolutionary history of lower Diptera, and Burmahesperinus gen. nov. is another illustration of this process. Numerous examples in modern fauna, as well as in the fossil record, show that the reduction and transformation of the antennae from the primitive multi-segmented type found in lower Diptera to the structure known in most Brachycera has occurred repeatedly, as Stuckenberg [28] extensively describes in examples of lower Brachycera. On the other hand, the opposite case of the flagellum with 14 fully developed flagellomeres is known in several taxa of lower Brachycera, e.g., in the genus Rachicerus Walker, 1854 (family Rachiceridae), where the male flagellum is even pectinate.

Since the number of flagellomeres cannot be exactly documented, we should compare Burmahesperinus gen. nov. also with Brachycera to exclude its placement there. Apart from the slender body, long palpi (at least four-segmented) and elongated legs, typical of the lower Diptera (Nematocera), the wing venation is the main argument for the placement of Burmahesperinus gen. nov. in Bibionomorpha rather than in Brachycera. Actually, Nematocera is currently considered as a paraphyletic group, hence suggested to be called just lower Diptera, and infraorders of Nematocera are sometimes considered as suborders of Diptera [29]. In any case, both Bibionomorpha and Brachycera represent sister groups, e.g., [6,30], altogether called Neodiptera [31], which means that the closest relative of Bibionomorpha is Brachycera, not the rest of lower Diptera. The new genus definitely belongs to Neodiptera and the modification of the antennae in Burmahesperinus may possibly be considered as another indication of the sister relationship of these two major groups of Diptera. Although many currently recognized synapomorphies defining Brachycera [30] are based on the morphology of the thorax, which is rarely preserved enough in fossils to allow seeing its detailed structure, or on larval structures, usually unknown in extinct taxa, we do not see any other characters (except for the modified antennae) in support of a possible inclusion of Burmahesperinus in Brachycera.

Another potentially remarkable feature is the asymmetry of the male terminalia, apparent in the holotype of $B$. conicus sp. nov. and also in one more specimen (without antennae) not included in this study. Having just two such specimens available, it is impossible to decide now if this is just an aberration in these specimens, a damage caused by the fossilization process, or a regular feature in this species or genus. We leave this issue as open to future studies because male terminalia of Bibionidae, while symmetrical, can look very different from various angles and in fossil specimens not all views are available. The (real) asymmetry of particular parts of the male terminalia is known to be independently developed in various groups of Diptera, both Nematocera and Brachycera, e.g., in Scatopsidae, Hybotidae, or Dolichopodidae [32,33].

Finally, we present here a short explanation of the wing vein nomenclature used in this paper. We consider Anisopodomorpha as the ancestral form of wing venation for Bibionomorpha. In Anisopodomorpha, there is the medial-basal vein $(\mathrm{Mb})$, which bifurcates into $\mathrm{M}_{1+2}$ and $\mathrm{M}_{3+4}$. In fact, we do not know if $\mathrm{M}_{3}$ disappeared by atrophy or if the veins $\mathrm{M}_{3}$ and $\mathrm{M}_{4}$ fused along their entire length; therefore, both interpretations may be correct $\left(\mathrm{M}_{4}\right.$ or $\left.\mathrm{M}_{3+4}\right)$. In our opinion, it is rather $\mathrm{M}_{3+4}$ than $\mathrm{M}_{4}$, i.e., the veins fused, based on the observation of wing vein changes in Anisopodomorpha and primitive Bibionomorpha. However, if $\mathrm{M}_{3}$ is considered as atrophied along its entire length, then the correct name would be $\mathrm{M}_{4}$. In any case, the basal part of either $\mathrm{M}_{3+4}$ or $\mathrm{M}_{4}$ is the remnant of $\mathrm{m}-\mathrm{cu}$, while the vein called bm-m in the Afrotropical Manual [26] is the basal part of $\mathrm{M}_{4}$ and in further development of Bibionomorpha, it atrophies. In Plecia Wiedemann, 1828, for example, crossvein bm-m equals $\mathrm{M}_{3+4}$, and it is actually the posterior wall of the discoid cell, i.e., the basal part of $\mathrm{M}_{3+4}$. In some species (as early as in Anispodomorpha), the basal part of $\mathrm{M}_{3+4}$ disappears, which can lead to misinterpretation of the veins. In Burmahesperinus, $\mathrm{Mb}$ forks into $\mathrm{M}_{1+2}$ and $\mathrm{M}_{3+4}$, and the basal part of the latter disappears (i.e., the fragment called as bm-m [26] disappears), while the end joining $\mathrm{Cu}$ is m-cu. Therefore, we think that the entire vein should be called $\mathrm{M}_{3+4}+\mathrm{m}-\mathrm{cu}$ (or $\mathrm{M}_{4}+\mathrm{m}-\mathrm{cu}$ ). This subject will be thoroughly treated in a separate paper under preparation (Krzeminski et al., in prep.). 


\section{Conclusions}

The new fossil genus, described in this paper, represents an interesting example of Brachycera-like modification of antennal flagellum within lower Diptera. We place it tentatively in the new subfamily (Burmahesperininae subfam. nov.) of the family Bibionidae, based mainly on the wing venation, pending further studies into the evolution of both recent and fossil Bibionomorpha.

Author Contributions: Conceptualization, J.Š., J.S., W.K., and K.S.; methodology, J.̌̌., J.S., W.K., and K.S.; validation, J.Š., J.S., W.K., and K.S.; investigation, J.Š., J.S., W.K., and K.S.; resources, J.Š., J.S., W.K., and K.S.; writing — original draft preparation, J.Š., J.S., W.K., and K.S.; writing—review and editing, J.Š., J.S., W.K., and K.S.; visualization, J.Š. and K.S.; supervision, J.Š., J.S., W.K., and K.S.; project administration, J.Š., K.S., and W.K.; funding acquisition, J.Š., K.S., and W.K. All authors have read and agreed to the published version of the manuscript.

Funding: This research was funded by National Science Centre of Poland (grant number UMO2016/23/B/NZ8/00936) and by the institutional support for the University of Ostrava provided by the Ministry of Education, Youth and Sports of the Czech Republic.

Acknowledgments: We are grateful to Peter Chandler, Scott Fitzgerald, and two anonymous reviewers for their valuable comments and suggestions on this manuscript.

Conflicts of Interest: The authors declare no conflict of interest. The funders had no role in the design of the study; in the collection, analyses, or interpretation of data; in the writing of the manuscript, or in the decision to publish the results.

\section{References}

1. Evenhuis, N. Catalog of the Fossil Flies of the World (Insecta: Diptera), Version 2.0. Available online: http:/ /hbs.bishopmuseum. org/fossilcat/ (accessed on 10 October 2020).

2. Van Nieukerken, E.J.; Kaila, I.J.; Kristensen, N.P.; Kristensen, N.P.; Lees, D.C.; Minet, J.; Mitter, C.; Mutanen, M.; Regier, J.C.; Simonsen, T.J.; et al. Animal biodiversity: An outline of higher-level classification and survey of taxonomic richness. Zootaxa 2011, 3148, 222-229.

3. Blagoderov, V.; Grimaldi, D.A.; Fraser, N.C. How Time Flies for Flies: Diverse Diptera from the Triassic of Virginia and Early Radiation of the Order. Am. Mus. Novit. 2007, 3572, 1-39. [CrossRef]

4. Shcherbakov, D.E.; Lukashevich, E.D.; Blagoderov, V.A. Triassic Diptera and initial radiation of the order. Int. J. Dipt. Res. 1995, 6, 75-115.

5. Krzeminski, W.; Krzeminska, E. Triassic Diptera: Descriptions, revisions and phylogenetic relations. Acta Zool. Cracov. 2003, 46, 153-184.

6. Ševčík, J.; Kasprák, D.; Mantič, M.; Fitzgerald, S.; Ševčíková, T.; Tóthová, A.; Jaschhof, M. Molecular phylogeny of the megadiverse insect infraorder Bibionomorpha sensu lato (Diptera). PeerJ 2016, 4, e2563. [CrossRef] [PubMed]

7. Mantič, M.; Sikora, T.; Burdíková, N.; Blagoderov, V.; Kjærandsen, J.; Kurina, O.; Ševčík, J. Hidden in Plain Sight: Comprehensive Molecular Phylogeny of Keroplatidae and Lygistorrhinidae (Diptera) Reveals Parallel Evolution and Leads to a Revised Family Classification. Insects 2020, 11, 348. [CrossRef]

8. Blagoderov, V.; Grimaldi, D. Fossil Sciaroidea (Diptera) in Cretaceous Ambers, Exclusive of Cecidomyiidae, Sciaridae, and Keroplatidae. Am. Mus. Novit. 2004, 3433, 1-76. [CrossRef]

9. Ševčík, J.; Krzemiński, W.; Skibińska, K. Intriguing and Beautiful: Adamacrocera adami gen. et sp. nov. from the Upper Cretaceous Amber of Myanmar Represents a New Subfamily of Keroplatidae (Diptera: Bibionomorpha). Insects 2020, 11, 552. [CrossRef]

10. Kalugina, N.S.; Kovalev, V.G. Two-Winged Flies of the Jurassic of Siberia; Nauka Press: Moscow, Russia, 1990; pp. 1-199.

11. Kovalev, V.G. Two-winged flies. Muscida. In Late Mesozoic Insects of Eastern Transbaikalia; Nauka Press: Moscow, Russia, 1990; pp. 123-177.

12. Skartveit, J.; Ansorge, J. A new genus and subfamily of fossil Bibionidae (Diptera) from the Lower Cretaceous, with new classification of the Bibionidae. Palaeoentomology 2020, 3, 163-172. [CrossRef]

13. Poinar, G. Cascoplecia insolitis (Diptera: Cascopleciidae), a new family, genus, and species of flower-visiting, unicorn fly (Bibionomorpha) in Early Cretaceous Burmese amber. Cretac. Res. 2010, 31, 71-76. [CrossRef]

14. Hardy, D.E. Bibionidae. In Manual of Nearctic Diptera; McAlpine, J.F., Peterson, B.V., Shewell, G.E., Teskey, H.J., Vockeroth, J.R., Wood, D.M., Eds.; Biosystematics Research Institute: Ottawa, ON, Canada, 1981; Volume 1, pp. 217-222, 674.

15. Fitzgerald, S.J. Bibionidae (March Flies, Love Bugs). In Manual of Central American Diptera; Brown, B.V., Borkent, A., Cumming, J.M., Wood, D.M., Woodley, N.E., Zumbado, M.A., Eds.; NRC Research Press: Ottawa, ON, Canada, 2009; Volume 1, pp. 245-251, 714.

16. Skartveit, J. Family Bibionidae. In Contributions to a Manual of Palaearctic Diptera; Papp, L., Darvas, B., Eds.; Science Herald: Budapest, Hungary, 1997; Volume 2, pp. 41-50, 592. 
17. Krivosheina, N.P. Pleciidae. In Catalogue of Palaearctic Diptera. Sciaridae-Anisopodidae; Soós, Á., Papp, L., Eds.; Akadémiai Kiadó: Budapest, Hungary, 1981; Volume 4, pp. 313-316, 441.

18. Fitzgerald, S.J. Evolution and Classification of Bibionidae (Diptera: Bibionomorpha). Ph.D. Thesis, State University, Corvallis, OR, USA, 2004.

19. Pinto, L.G.; Amorim, D.S. Bibionidae (Diptera: Bibionomorpha). In Morfologia e Análise Filogenética; Holos: Ribeirão Preto, Brazil, 2000.

20. Grimaldi, D.; Amorim, D.S.; Blagoderov, V. The Mesozoic Family Archizelmiridae (Diptera: Insecta). J. Paleontol. 2003, 77, 368-381. [CrossRef]

21. Krzemińska, E.; Krzemiński, W.; Dahl, C. Monograph of Fossil Trichoceridae (Diptera) over 180 Million Years of Evolution; Institute of Systematic and Evolution of Animals Polish Academy of Sciences: Krakow, Poland, 2009; pp. 1-171.

22. Cruickshank, R.D.; Ko, K. Geology of an amber locality in the Hukawng Valley, northern Myanmar. J. Asian Earth Sci. 2003, 21, 441-445. [CrossRef]

23. Grimaldi, D.A.; Engel, M.S.; Nascimbene, P.C. Fossiliferous Cretaceous amber from Myanmar (Burma): Its rediscovery, biotic diversity, and paleontological significance. Am. Mus. Novit. 2002, 3361, 1-71. [CrossRef]

24. Shi, G.; Grimaldi, D.A.; Ge, H.; Wang, J.; Yang, M.; Lei, W.; Li, Q.; Li, X. Age constraint on Myanmar amber based on U-Pb dating of zircons. Cretac. Res. 2012, 37, 155-163. [CrossRef]

25. Skartveit, J. Fossil Hesperinidae and Bibionidae (Diptera: Bibionoidea) from Baltic amber. Stud. Dipterol. 2008, $15,3-42$.

26. Skartveit, J. Bibionidae. In Manual of Afrotropical Diptera. Nematocerous Diptera and Lower Brachycera; Kirk-Spriggs, A.H., Sinclair, B.J., Eds.; Suricata 5; SANBI Graphics \& Editing: Pretoria, South Africa, 2017; Volume 2, pp. 425, 497-504.

27. Arillo, A.; Blagoderov, V.; Peñalver, E. Early Cretaceous parasitism in amber: A new species of Burmazelmira fly (Diptera: Archizelmiridae) parasitized by a Leptus sp. mite (Acari, Erythraeidae). Cretac. Res. 2018, 86, 24-32. [CrossRef]

28. Stuckenberg, B.R. Antennal evolution in the Brachycera (Diptera), with a reassessment of terminology relating to the flagellum. Stud. Dipterol. 1999, 6, 33-48.

29. Amorim, D.S.; Yeates, D. Pesky gnats: Ridding dipteran classification of the "Nematocera". Stud. Dipterol. 2006, 13, 3-9.

30. Lambkin, C.L.; Sinclair, B.J.; Pape, T.; Courtney, G.W.; Skevington, J.H.; Meier, R.; Yeates, D.K.; Blagoderov, V.; Wiegmann, B.M. The phylogenetic relationships among infraorders and superfamilies of Diptera based on morphological evidence. Syst. Entomol. 2013, 38, 164-179. [CrossRef]

31. Michelsen, V. Neodiptera: New insights into the adult morphology and higher level phylogeny of Diptera (Insecta). Zool. J. Linn. Soc. 1996, 117, 71-102. [CrossRef]

32. Sinclair, B.J.; Cumming, J.M.; Brooks, S.E. Male terminalia of Diptera (Insecta): A review of evolutionary trends, homology and phylogenetic implications. Insect Syst. Evol. 2013, 44, 373-415. [CrossRef]

33. Huber, B.A.; Sinclair, B.J.; Schmitt, M. The evolution of asymmetric genitalia in spiders and insects. Biol. Rev. 2007, 82, 647-698. [CrossRef] [PubMed] 